\title{
Activity of Aloe vera, Apium graveolens and Sauropus androgynus Alcoholic Extracts against Methicillin- Resistant Staphylococcus aureus
}

\author{
Yos Adi Prakoso $^{1,2}$, Kurniasih ${ }^{3 *}$, Agustina Dwi Wijayanti ${ }^{4}$ and Yuli Purwandari Kristianingrum ${ }^{3}$ \\ ${ }^{I}$ Doctoral Program in Veterinary Science, Faculty of Veterinary Medicine, University of Gadjah Mada, Yogyakarta, 55281, Indonesia \\ ${ }^{2}$ Faculty of Veterinary Medicine, University of Wijaya Kusuma Surabaya, East Java, 60225, Indonesia \\ ${ }^{3}$ Department of Pathology, Faculty of Veterinary Medicine, University of Gadjah Mada, Yogyakarta, 55281, Indonesia \\ ${ }^{4}$ Department of Pharmacology, Faculty of Veterinary Medicine, University of Gadjah Mada, Yogyakarta, 55281, Indonesia \\ *Corresponding author's Email: kurniasih_1951@yahoo.co.id; (DORCiD: 0000-0002-4787-8692
}

\begin{abstract}
Staphylococcus aureus is a Gram-positive bacteria that influence human health. Staphylococcus aureus becomes a more serious problem if it is resistant to methicillin. This phenomenon is known as methicillin-resistant Staphylococcus aureus (MRSA). This study aimed to elucidate the chemical compounds, antioxidant activity and efficacy of Aloe vera (AV), Apium graveolens (AG), Sauropus androgynus (SA) extracts and its combinations against MRSA. All the herbs were extracted and determined its antioxidant constituent and 2,2-diphenyl-1picrylhydrazyl (DPPH) scavenging activity using a standard laboratory procedure. The MRSA isolates were tested against AV, AG, SA extracts and its combinations using disc diffusion and minimum inhibitory concentration (MIC) test. Further exploration was conducted using scanning electron microscope (SEM) to analyse the MRSA membrane after the treatment with 10,000 $\times$ of magnification. The data was analysed using one-way ANOVA and post hoc test. The result showed that AG extract has the highest phytochemical screening and antimicrobial effects compared to the other single extract (AV and SA), even though, it has the lowest DPPH scavenging activity. The extract combinations did not consistently increase phytochemical content, antimicrobial effect, and DPPH scavenging activity of the herb extracts. However, one $\mathrm{mg} / \mathrm{mL}$ of dose of herbal extracts and its combinations could be used as the minimum dose to inhibit colonisation of MRSA in vitro. Further, SEM examination showed that $1 \mathrm{mg} / \mathrm{mL} \mathrm{of}$ dose destructed the MRSA membrane rigidity which was proved by non-uniformity of bacterial cell architecture. This in vitro study indicated that AV, AG and SA extracts and its combinations can utilize as the therapy against MRSA.
\end{abstract}

Key words: Aloe vera, Antioxidant, Apium graveolens, Methicillin - Resistant Staphylococcus aureus, Sauropus androgynus

\section{INTRODUCTION}

Staphylococcus aureus is a Gram-positive bacteria that succeed form biofilms that can be isolated from various wound types (Fadeev and Nemtseva, 2009). S. aureus becomes more dangerous if it is resistant against commercial antibiotics including methicillin. This phenomenon is identified as methicillin-resistant Staphylococcus aureus (MRSA) (Carroll, 2008). Moreover, these bacteria contain several virulence factors such as Panton-Valentine leukocidin (PVL), staphylococcal protein-A (sp-A), and $\alpha$-hemolysin (HLA) (Ali et al., 2018), that support its pathogenicity during the infection (Otto, 2010) including purulent mass in the joints (Babazadeh et al., 2015). The MRSA infection commonly occurs in the patients and hospital workers, and it is known as hospital-acquired MRSA (HA-MRSA) (Durai et al., 2010). HA-MRSA causes high medication cost, chronic infection and death. The treatment of MRSA infection must follow the medical guideline and as much as possible to minimise the utilisation of antibiotics. The herbal medication is expected to support the therapy of MRSA in both decreases the medication cost and promote the healing.

Aloe vera (AV), Apium graveolens (AG), and Sauropus androgynus (SA) are the common herbs that can be found in a tropical area. Those herbs have been utilised for a long decade because of its pluripotential activity on human health. $\mathrm{AV}$ is the most commercialised herbs in dermatological industries worldwide (Hamman, 2008). The inner gel of AV stimulates the reticuloendothelial cells (Talmadge et al., 2004) and healing (Prakoso and Kurniasih, 2018). Further, the AV extract is potential to enhance the absorption of drug via intestinal villi in vitro (Haasbroek et al., 2019). It has been utilised as the antibacterial agents against Staphylococcus aureus and Pseudomonas aeruginosa, and its activity significantly increases when it combined with chitosan and silver nanoparticles (Chabala et al., 2017).

In addition, AG is widely used as antioxidative agents. The previous study describes that AG has published up to 980-articles from 1997-2015 (Kooti and Daraei, 2017). It proves that AG is potential as an herbal remedy. The antioxidants insides the AG are utilised as the antiparasite (Kumar et al., 2014), antitumour (Danciu et al., 2018) and antibacterial agents (Powanda et al., 2015). The other herb is SA which contains several active constituents such as 
glycoside, flavonoid, and alkaloid that potential as the antitoxic and antioxidant (Prabhu et al., 2015). The utilisation of SA was reported to decrease the risk of aflatoxicosis and bacterial infection (Bose et al., 2018). Nevertheless, the potency of those extracts on the MRSA has not been explored by the previous study, therefore this study aimed to explore the chemical constituent, antioxidant activity, and the potency of AV, AG, and SA extracts and its combination against the MRSA.

\section{MATERIALS AND METHODS}

\section{The types of herbs}

All the herbs were collected from the herbal store in Batu, Malang, East Java, Indonesia. The herbal species were then determined by Plant Conservation Center, Botanical Garden of Purwodadi, Indonesian Institute of Sciences with the voucher number: 0276-0278/ IPH.06/HM/II/2019.

\section{Extraction}

This study was conducted between February-May 2019 in the Integrated Laboratory, Faculty of Health, University of Muhammadiyah Sidoarjo, East Java, Indonesia. All the herbs were dried using aerated methods. The dried herb was then mashed up using the electric blender. The herbal powders were weighed and soaked using $70 \%$ alcohol in 1:4 of proportion. The maceration was conducted and filtered three times, and the filtrate was then evaporated using evaporator (Prakoso and Kurniasih, 2018).

\section{Experimental design}

Following the extraction, the herbal extracts were mixed (1:1) as follow: AV, AG, SA, AV + AG, AV + SA, AG + $\mathrm{SA}$, and $\mathrm{AV}+\mathrm{AG}+\mathrm{SA}$. Each extract was then tested its chemical constituent using qualitative and quantitative methods and its radical scavenging activity as described below.

\section{Qualitative and quantitative phytochemical screening}

Each extract was tested for several components such as alkaloid, flavonoid, saponin, steroid, triterpenoid, phenolic, glycoside, carotenoid, and tannin. The extracts active ingredients were analysed using qualitative following the standard laboratory procedure as follow (Prakoso et al., 2018). The alkaloid was screened using Mayer, Wagner, and Dragendorf test; flavonoid by the reaction of magnesium, hydrogen chloride, and ethanol; saponin by the appearance of foam; steroid by Libermann-Burchard; triterpenoid by chloroform and sulphuric acid; phenolic by $10 \%$ natrium chloride and $1 \%$ gelatin; glycoside by Borntrager's methods; carotenoid by chloroform and $85 \%$ sulphuric acid; and tannin using $1 \%$ ferric chloride.The quantitative phytochemical of the herbal extracts were conducted using the procedure demonstrated in 2017 by (Ajuru et al., 2017).

\section{2, 2-diphenyl-1-picrylhydrazyl radical scavenging activity}

The radical scavenging activity was measured using ultraviolet-visible (UV-Vis) spectrophotometer. UV-Vis method has utilized the scavenging of 2, 2-diphenyl-1-picrylhydrazyl (DPPH). Seven hundred and fifty $\mu \mathrm{L}$ of herbal extracts and $750 \mu \mathrm{L}$ of standard antioxidant were weighed and diluted using two-fold of methanolic DPPH solution. The solution was then mixed in room temperature. The absorbance value was measured at $517 \mathrm{~nm}$, and the results were expressed as $\mathrm{SC}_{50}$. Lower $\mathrm{SC}_{50}$ indicated high radical scavenging activity (Akar et al., 2017).

\section{Methicillin resistant Staphylococcus aureus isolate}

The MRSA isolate was obtained from the Dept. Microbiology, Faculty of Medicine, University of Airlangga, Surabaya, East Java, Indonesia with authentication number: 53/UN3.1.1/MK/LL/2019. The isolation procedure was conducted by clinical microbiology specialist and laboratory technician. The MRSA isolate was cultured on the blood agar with $15 \mathrm{mg}$ nalidixic and $10 \mathrm{mg}$ colistin sulphate. The media was then incubated in $37^{\circ} \mathrm{C}$ for 24 hours. The colonies were tested following the protocol demonstrated in 2013 by (Missiakas and Scheneewind, 2013). The MRSA confirmation was conducted using 30 ug cefoxitin test (Adhikari et al., 2017).

\section{Disc diffusion test}

The antimicrobial susceptibility test was performed using the Kirby-Bauer methods. The MRSA isolate was cultured on the enrichment media for 6 hours until its turbidity showed a $0.5 \mathrm{McFarland}$ standard. The suspension was spread on the Muller Hinton Agar (MHA). The blank disc was impregnated with AV, AG, SA, AV + AG, AV + SA, AG $+\mathrm{SA}$, and $\mathrm{AV}+\mathrm{AG}+\mathrm{SA}$ extracts using several concentration as follow $0 \%, 10 \%, 20 \%, 30 \%, 40 \%, 50 \%, 60 \%, 70 \%$, $80 \%, 90 \%, 100 \%$. Each concentration was replicated six times. The plates were incubated for $37^{\circ} \mathrm{C}$ for 24 hours. The 
results were reported as the diameter of inhibition and Percentage Inhibition of Diameter Growth (PIDG) (HimratulAznita et al., 2011).

\section{Minimum inhibitory concentration}

Minimum Inhibitory Concentration (MIC) was conducted by the dilution of the extracts. One hundred $\mu \mathrm{L}$ stock solution of the extract was added into well. Half part of the extract was then moved to the other well until reaching zero concentration. A total of $100 \mu \mathrm{L}$ MRSA suspension was added and covered using the lid. It was incubated at $37^{\circ} \mathrm{C}$ for 24 hours. The absorbance of the suspension was measured using a spectrophotometer. The MIC was determined by the minimal concentration that invisible the growing of bacteria (Bussmann et al., 2010).

\section{Ultrastructural study}

Following the MIC, the bacteria was centrifuged at $1500 \mathrm{rpm}$ for 5 minutes. The supernatant was thrown away. Two per cent of glutaraldehyde was added and incubated for 3 hours. The suspension was centrifuged and replaced by $2 \%$ tannin acid for 6 hours. Caccodylate buffer was added and followed by $1 \%$ osmium tetroxide. The dehydration was conducted using graded alcohol. The bacteria was then coated with gold and carbon in sputter coater and the microscopy was performed using JSM5000 Scanning Electron Microscope (SEM) with 10,000× magnification. Figure analysis was examined using image software to measure the diameter of bacteria after treatment using herbs extracts (Zajmi et al., 2015).

\section{Analysis data}

The data of qualitative phytochemical screening were descriptively analysed. However, the data of quantitative phytochemical screening, DPPH radical scavenging activity, complete inhibition zone, PIDG and MIC were quantified using one-way ANOVA and post hoc test with a probability value at level of $\mathrm{P}<0.05$.

\section{RESULTS}

\section{Qualitative and quantitative phytochemical screening}

Based on the phytochemical screening, all the herbal extracts have a different chemical constituent. AG and SA contained all of the measured chemical constituents, however, AV was not contained the phenolic compound. The qualitative screening showed that the mixture of the extract did not always increase the chemical constituents of the herbs extracts (Table 1). As a single extract, the AV extract contains the highest alkaloid, saponin and tannin level compared to the others. On the other hands, AG extract contains the highest phenolic and flavonoid level compared to the others. Based on the findings, the combination of $\mathrm{AV}+\mathrm{AG}+\mathrm{SA}$ increased the alkaloid, phenolic, and saponin level of the extract. Furthermore, the mixture of the extract did not consistently increase the level of quantitative phytochemical screening, especially for flavonoid and tannin contents. Those results were different from the qualitative phytochemical screening. It may be caused by the detection limit of the qualitative screening and its standard error. The quantitative phytochemical screening results were shown in table 2.

Table 1. Qualitative phytochemical screening of the herbal extracts and its combinations.

\begin{tabular}{|c|c|c|c|c|c|c|c|}
\hline \multirow{2}{*}{ Parameters } & \multicolumn{7}{|c|}{ Phytochemical compound } \\
\hline & $\mathrm{AV}$ & $\mathrm{AG}$ & SA & $\mathrm{AV}+\mathrm{AG}$ & $\mathrm{AV}+\mathrm{SA}$ & $\mathrm{AG}+\mathrm{SA}$ & $\mathrm{AV}+\mathrm{AG}+\mathrm{SA}$ \\
\hline Alkaloid W & ++ & + & ++ & ++ & ++ & ++ & ++ \\
\hline Alkaloid M & ++ & ++ & ++ & +++ & +++ & +++ & +++ \\
\hline Alkaloid D & +++ & +++ & ++ & +++ & +++ & +++ & +++ \\
\hline Carotenoid & + & + & +++ & ++ & ++ & +++ & +++ \\
\hline Flavonoid & +++ & +++ & ++ & ++ & ++ & +++ & +++ \\
\hline Glycoside & + & ++ & +++ & ++ & ++ & +++ & +++ \\
\hline Phenolic & - & +++ & +++ & +++ & ++ & ++ & +++ \\
\hline Saponin & +++ & ++ & ++ & +++ & ++ & +++ & +++ \\
\hline Steroid & +++ & +++ & +++ & +++ & +++ & +++ & +++ \\
\hline Tannin & + & + & + & + & + & ++ & ++ \\
\hline Triterpenoid & + & + & + & + & + & ++ & ++ \\
\hline
\end{tabular}

$\overline{\mathrm{AV}}=$ Aloe vera $; \mathrm{AG}=$ Apium graveolens $; \mathrm{SA}=$ Sauropus androgynus $; \mathrm{W}=$ Wagner; $\mathrm{M}=$ Mayer; $\mathrm{D}=\mathrm{Dragendorf} ;++=$ low positive $;++=$ moderate positive; $+++=$ strong positive; - = negative. 


\section{2, 2-diphenyl-1-picrylhydrazyl radical scavenging activity}

As the stable free radical, the DPPH is commonly used as the parameter to measure the herb's antioxidant activity. The minimal concentration of antioxidant that causing 50\% scavenging of DPPH was considered as the highly potent antioxidant. It is mean that lower $\mathrm{SC}_{50}$ of antioxidant indicates high scavenging activity. This study proved that $\mathrm{AV}$ has better $\mathrm{SC}_{50}$ compared to $\mathrm{SA}$ and $\mathrm{AG}$. The herb extract combination showed better DPPH scavenging activity compared to its single extract types (Figure 1). The extracts antioxidant activity can be ranked as AV + AG + SA > AV + SA > AV $>\mathrm{AV}+\mathrm{AG}>\mathrm{SA}>\mathrm{AG}+\mathrm{SA}>\mathrm{AG}$. As a single extract and combination, the AV has a consistent profile regarding the DPPH scavenging activity

Table 2. Quantitative phytochemical screening of the herbal extracts and its combinations.

\begin{tabular}{lccccccc}
\hline \multirow{2}{*}{ Parameters } & \multicolumn{7}{c}{ Phytochemical compound (\%) \pm standard of deviation (SD) } \\
\cline { 2 - 8 } & AV & AG & SA & AV + AG & AV + SA & AG + SA & AV+AG+SA \\
\hline Alkaloid & $18.73 \pm 1.49^{\mathrm{a}}$ & $14.91 \pm 0.63^{\mathrm{b}}$ & $13.69 \pm 0.52^{\mathrm{b}}$ & $20.76 \pm 0.53^{\mathrm{a}}$ & $22.15 \pm 0.96^{\mathrm{c}}$ & $20.09 \pm 0.09^{\mathrm{a}}$ & $21.82 \pm 1.54^{\mathrm{c}}$ \\
Flavonoid & $9.24 \pm 0.89^{\mathrm{a}}$ & $10.35 \pm 0.87^{\mathrm{a}}$ & $6.89 \pm 0.43^{\mathrm{b}}$ & $8.03 \pm 0.13^{\mathrm{a}}$ & $7.46 \pm 0.52^{\mathrm{b}}$ & $10.01 \pm 0.17^{\mathrm{a}}$ & $10.12 \pm 0.94^{\mathrm{a}}$ \\
Phenolic & $0.52 \pm 0.57^{\mathrm{a}}$ & $23.07 \pm 2.55^{\mathrm{b}}$ & $18.52 \pm 0.63^{\mathrm{b}}$ & $22.08 \pm 2.65^{\mathrm{b}}$ & $19.13 \pm 1.58^{\mathrm{b}}$ & $19.31 \pm 0.53^{\mathrm{b}}$ & $26.30 \pm 0.63^{\mathrm{b}}$ \\
Saponin & $3.67 \pm 0.56^{\mathrm{a}}$ & $2.40 \pm 0.46^{\mathrm{b}}$ & $0.99 \pm 0.14^{\mathrm{b}}$ & $3.50 \pm 0.43^{\mathrm{a}}$ & $2.36 \pm 0.43^{\mathrm{b}}$ & $3.21 \pm 0.76^{\mathrm{a}}$ & $3.68 \pm 0.44^{\mathrm{a}}$ \\
Tannin & $1.79 \pm 0.52^{\mathrm{a}}$ & $0.94 \pm 0.09^{\mathrm{b}}$ & $0.63 \pm-0.10^{\mathrm{b}}$ & $2.10 \pm 0.07^{\mathrm{a}}$ & $1.77 \pm 0.64^{\mathrm{a}}$ & $2.11 \pm 0.98^{\mathrm{a}}$ & $2.05 \pm 0.13^{\mathrm{a}}$ \\
\hline
\end{tabular}

$\mathrm{AV}=$ Aloe vera $; \mathrm{AG}=$ Apium graveolens $; \mathrm{SA}=$ Sauropus androgynus $;{ }^{\mathrm{a}, \mathrm{b}}$ The different superscript on the same row showed significantly different value $(\mathrm{P}<0.05)$.

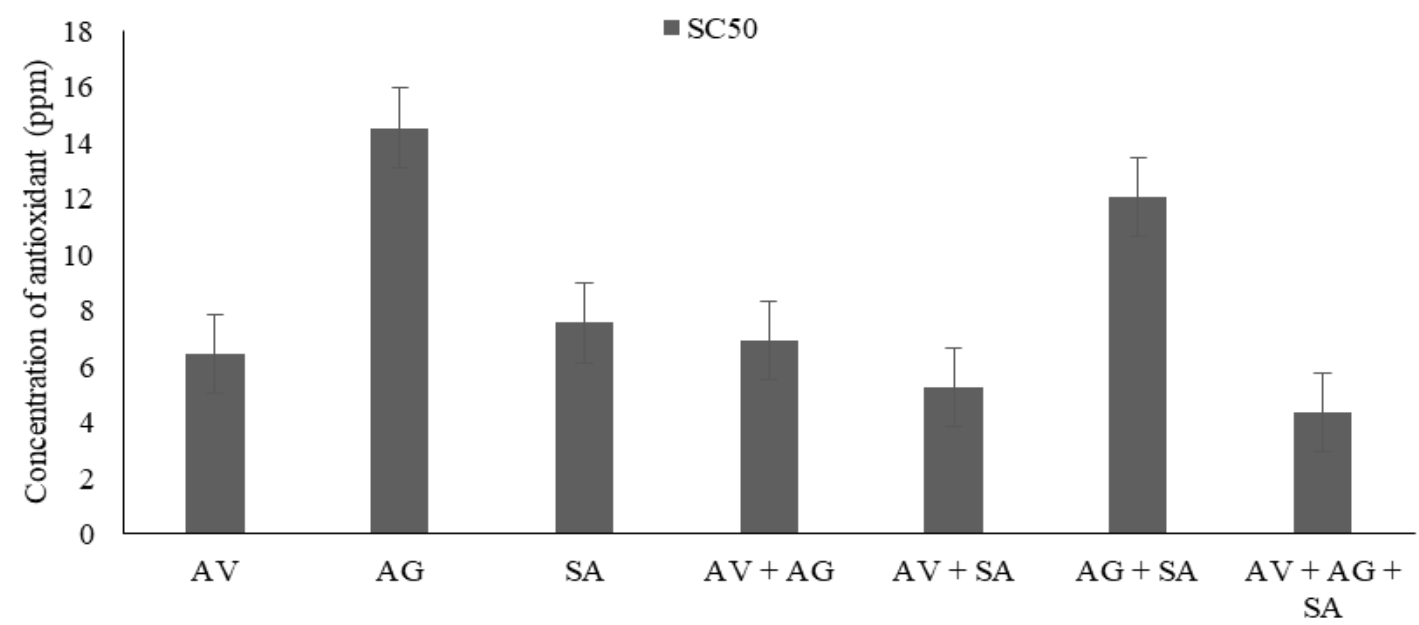

Figure 1. $\mathrm{SC}_{50}$ value of herbal extracts and its combinations that causing 50\% 2,2-diphenyl-1-picrylhydrazyl scavenging. AV: Aloe vera; AG: Apium graveolens; SA: Sauropus androgynus.

\section{Inhibition zone and percentage inhibition of diameter growth}

This study showed that complete inhibition zone occurs on various concentration. The complete inhibition zone of MRSA formed is categorised as susceptible, intermediate, and resistant. At the lowest DPPH scavenging activity, AG has a better antibacterial activity that proved by its complete inhibition zone in an intermediate profile $(14.84 \mathrm{~mm})$ at $40 \%$ concentration that is similar to the $\mathrm{AV}+\mathrm{AG}+\mathrm{SA}$ extract combination. However, the other extracts and combinations showed that intermediate and susceptible profile starts at $60 \%$ concentration. The potency of antimicrobial effects on the disc diffusion method can be ranked as $\mathrm{AV}+\mathrm{AG}+\mathrm{SA}>\mathrm{AG}+\mathrm{SA}>\mathrm{AG}>\mathrm{AV}+\mathrm{AG}>\mathrm{AV}>\mathrm{AV}+\mathrm{SA}>\mathrm{SA}$ (Table 3).

Those effects were then analysed to determine its PIDG. The PIDG showed similar results to the disc diffusion test. Furthermore, the herb extract combinations showed a synergistic effect on the inhibition of MRSA in vitro. It is proved by the high PIDG value of herb extract combination of AV + AG + SA compared to the others (Table 3 and figure 2).

\section{Minimum inhibitory concentration}

The MIC was conducted using $60 \mathrm{mg} / \mathrm{mL}$ as the highest dosage against MRSA. The absorbance value of MRSA showed that all herbal extracts and its combinations are potentially significant to inhibit the MRSA at one $\mathrm{mg} / \mathrm{mL}$ of dose $(\mathrm{P}<0.05)$. The greater effects were shown by all herbal extracts and its combination at higher doses. This study proved that AV, AG, SA, and its combination synergically inhibit MRSA (Figure 3). 
Table 3. Complete inhibition zone ( $\mathrm{mm})$ of herbal extracts and its combinations.

\begin{tabular}{lccccccc}
\hline \multirow{2}{*}{$\begin{array}{l}\text { Concent } \\
\text { ration }\end{array}$} & \multicolumn{7}{c}{ Complete inhibition zone (mm) \pm standard of deviation (SD) } \\
\cline { 2 - 7 } & AV & AG & SA & AV + AG & AV + SA & AG + SA & AV+AG+SA \\
\hline $0 \%$ & $6.00 \pm 0.00^{\mathrm{a}}$ & $6.00 \pm 0.00^{\mathrm{a}}$ & $6.00 \pm 0.00^{\mathrm{a}}$ & $6.00 \pm 0.00^{\mathrm{a}}$ & $6.00 \pm 0.00^{\mathrm{a}}$ & $6.00 \pm 0.00^{\mathrm{a}}$ & $6.00 \pm 0.00^{\mathrm{a}}$ \\
$10 \%$ & $6.00 \pm 0.00^{\mathrm{a}}$ & $7.52 \pm 0.41^{\mathrm{a}}$ & $6.00 \pm 0.00^{\mathrm{a}}$ & $6.00 \pm 0.00^{\mathrm{a}}$ & $6.00 \pm 0.00^{\mathrm{a}}$ & $7.53 \pm 0.25^{\mathrm{a}}$ & $8.18 \pm 0.04^{\mathrm{a}}$ \\
$20 \%$ & $6.10 \pm 0.00^{\mathrm{a}}$ & $10.16 \pm 0.14^{\mathrm{a}}$ & $6.00 \pm 0.00^{\mathrm{a}}$ & $6.40 \pm 0.10^{\mathrm{a}}$ & $6.23 \pm 0.05^{\mathrm{a}}$ & $9.68 \pm 0.12^{\mathrm{a}}$ & $10.29 \pm 0.28^{\mathrm{a}}$ \\
$30 \%$ & $8.37 \pm 0.47^{\mathrm{a}}$ & $12.34 \pm 0.13^{\mathrm{a}}$ & $8.38 \pm 0.39^{\mathrm{a}}$ & $8.61 \pm 0.50^{\mathrm{a}}$ & $7.50 \pm 0.35^{\mathrm{a}}$ & $11.21 \pm 0.00^{\mathrm{a}}$ & $12.30 \pm 0.09^{\mathrm{a}}$ \\
$40 \%$ & $10.11 \pm 0.15^{\mathrm{a}}$ & $14.84 \pm 0.11^{\mathrm{b}}$ & $10.51 \pm 0.33^{\mathrm{a}}$ & $10.24 \pm 0.04^{\mathrm{a}}$ & $9.21 \pm 0.03^{\mathrm{a}}$ & $13.27 \pm 0.29^{\mathrm{a}}$ & $14.31 \pm 0.16^{\mathrm{b}}$ \\
$50 \%$ & $12.33 \pm 0.48^{\mathrm{a}}$ & $17.60 \pm 0.47^{\mathrm{b}}$ & $12.10 \pm 0.17^{\mathrm{a}}$ & $12.88 \pm 0.01^{\mathrm{a}}$ & $11.41 \pm 0.14^{\mathrm{a}}$ & $16.66 \pm 0.15^{\mathrm{b}}$ & $16.76 \pm 0.05^{\mathrm{b}}$ \\
$60 \%$ & $14.27 \pm 0.09^{\mathrm{b}}$ & $18.35 \pm 0.29^{\mathrm{c}}$ & $13.94 \pm 0.69^{\mathrm{b}}$ & $14.55 \pm 0.06^{\mathrm{b}}$ & $13.26 \pm 0.25^{\mathrm{b}}$ & $18.31 \pm 0.17^{\mathrm{c}}$ & $18.24 \pm 0.05^{\mathrm{c}}$ \\
$70 \%$ & $16.16 \pm 0.27^{\mathrm{b}}$ & $19.17 \pm 0.11^{\mathrm{c}}$ & $16.64 \pm 0.19^{\mathrm{b}}$ & $16.58 \pm 0.41^{\mathrm{b}}$ & $14.60 \pm 0.11^{\mathrm{b}}$ & $20.58 \pm 0.20^{\mathrm{c}}$ & $20.24 \pm 0.17^{\mathrm{c}}$ \\
$80 \%$ & $17.68 \pm 1.44^{\mathrm{b}}$ & $20.32 \pm 0.40^{\mathrm{c}}$ & $17.33 \pm 0.19^{\mathrm{b}}$ & $18.95 \pm 0.05^{\mathrm{b}}$ & $16.71 \pm 0.13^{\mathrm{b}}$ & $22.37 \pm 0.20^{\mathrm{c}}$ & $22.50 \pm 0.09^{\mathrm{c}}$ \\
$90 \%$ & $20.10 \pm 0.09^{\mathrm{b}}$ & $22.59 \pm 0.45^{\mathrm{c}}$ & $18.30 \pm 0.26^{\mathrm{b}}$ & $20.45 \pm 0.10^{\mathrm{b}}$ & $18.44 \pm 0.31^{\mathrm{b}}$ & $24.35 \pm 0.37^{\mathrm{c}}$ & $24.71 \pm 0.07^{\mathrm{c}}$ \\
$100 \%$ & $22.37 \pm 0.21^{\mathrm{c}}$ & $24.47 \pm 0.32^{\mathrm{c}}$ & $20.05 \pm 0.06^{\mathrm{b}}$ & $22.68 \pm 0.01^{\mathrm{b}}$ & $20.15 \pm 0.00^{\mathrm{b}}$ & $26.16 \pm 0.15^{\mathrm{c}}$ & $26.76 \pm 0.04^{\mathrm{c}}$ \\
\hline
\end{tabular}

AV: Aloe vera; AG: Apium graveolens; SA: Sauropus androgynus.; ${ }^{\mathrm{a}, \mathrm{b}}$ The different superscript on the same row showed significantly different value $(\mathrm{P}<0.05)$.

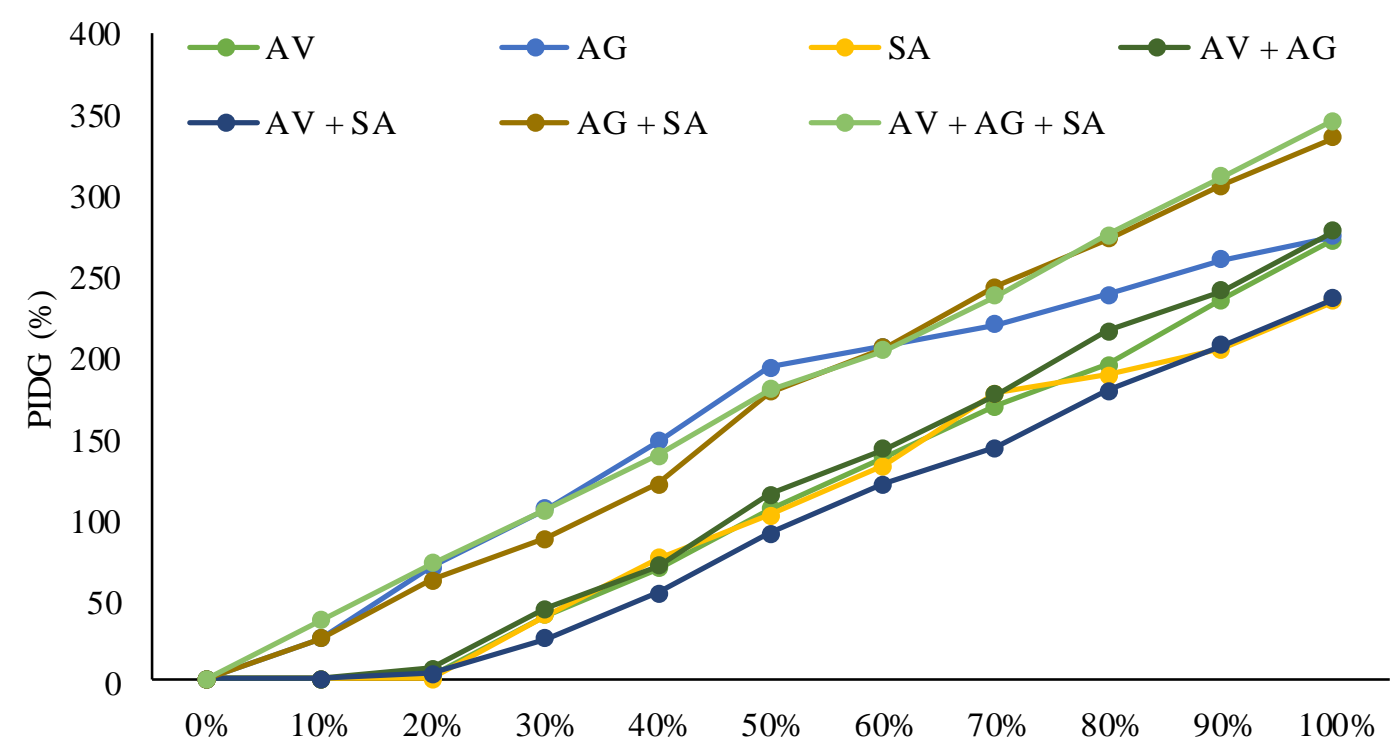

Figure 2. The effects of herbal extracts and its combinations on percentage of inhibition of diameter growth of the methicillin resistant Staphylococcus aureus in vitro. AV: Aloe vera; AG: Apium graveolens; SA: Sauropus androgynus.

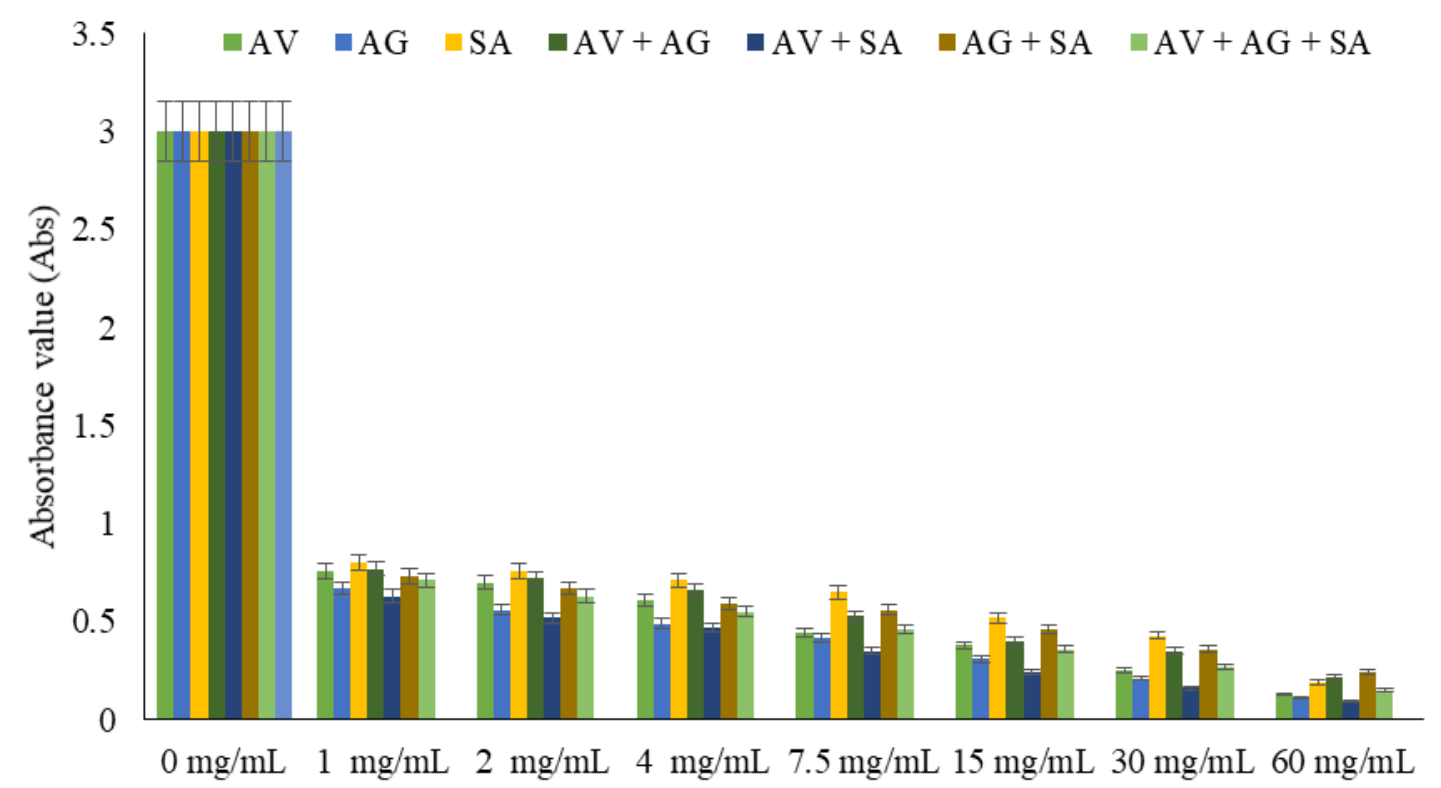

Figure 3. The effects of herbal extracts and its combinations on the absorbance value of methicillin resistant Staphylococcus aureus suspension. AV: Aloe vera; AG: Apium graveolens; SA: Sauropus androgynus. 
Ultrastructure of methicillin-resistant Staphylococcus aureus treated with AV, AG, SA and its combination

Based on the electron microscopy examination showed that MRSA has a cocci architecture and, it is similar to the grape shape with wrinkled cell walls The control showed the uniform shape with average bacteria cells diameter of 0.38 $\mu \mathrm{m}$ (Figure 4A). The different appearance was shown by the other groups treated with extracts of AV, AG, SA, and a combination of $\mathrm{AV}+\mathrm{AG}+\mathrm{SA}$. Those extracts in one $\mathrm{mg} / \mathrm{mL}$ of dose destructed bacterial wall rigidity such as broke membrane thickness. Furthermore, it promoted the shrinkage of bacterial cells that proved by the average bacterial cells diameters of $0.23 \mu \mathrm{m}(\mathrm{AV}), 0.18 \mu \mathrm{m}$ (AG), $0.20 \mu \mathrm{m}$ (SA), $0.17 \mu \mathrm{m}(\mathrm{AV}+\mathrm{AG}+\mathrm{SA}$ ) (Figure 4B and figure 4E). This study represents that the $\mathrm{AV}, \mathrm{AG}, \mathrm{SA}$ and $\mathrm{AV}+\mathrm{AG}+\mathrm{SA}$ could be used as the new herbal medicine and or candidate of therapy of MRSA infection. However, the in vivo study may need to elucidate its other positive effects of those extracts

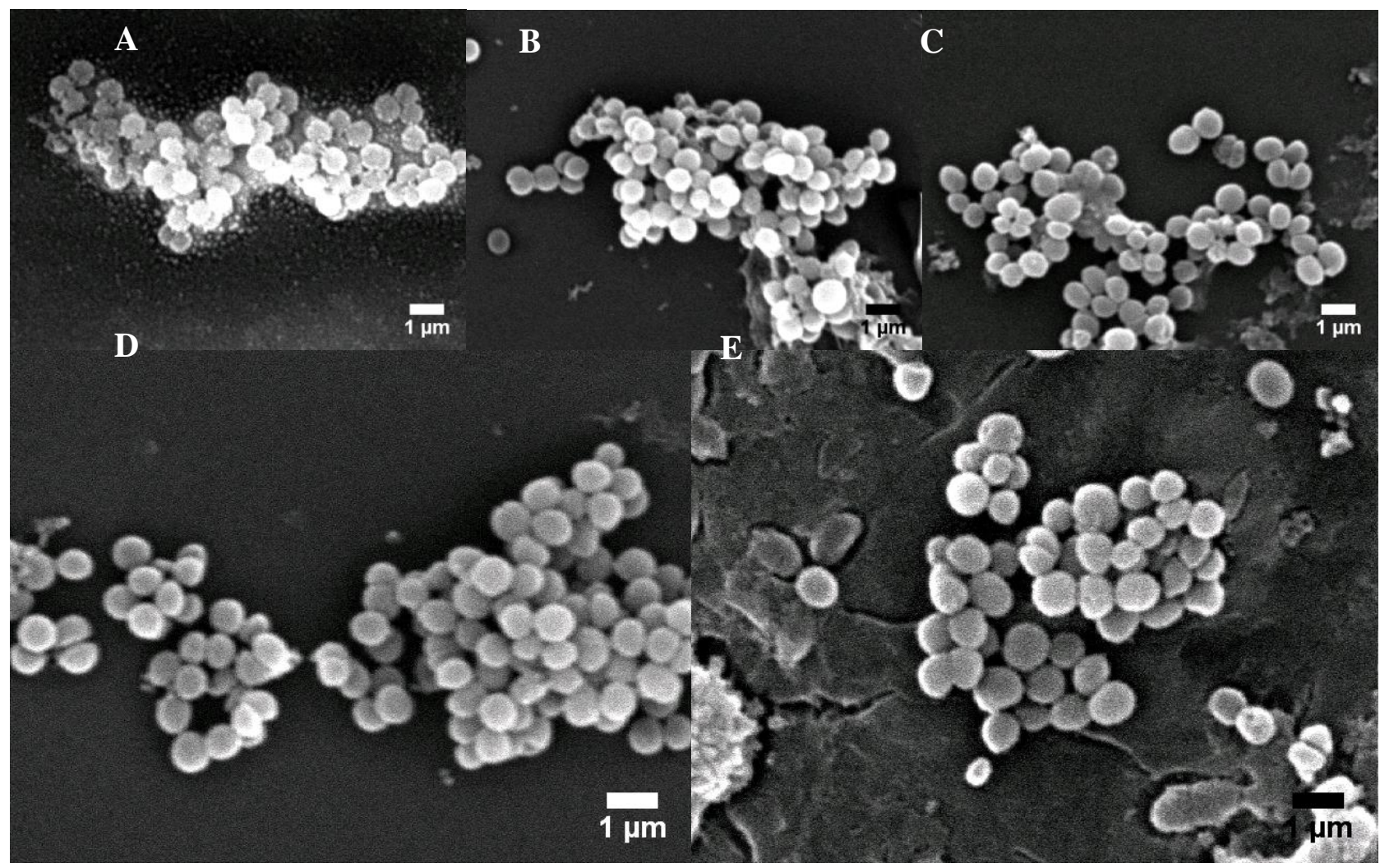

Figure 4. Ultrastructure of methicillin resistant Staphylococcus aureus after exposed to minimum inhibitory concentration of Aloe vera, Apium graveolens, Sauropus androgynus and Aloe vera + Apium graveolens + Sauropus androgynus for 24 hours. Methicillin resistant Staphylococcus aureus without treatment (A), treated with one $\mathrm{mg} / \mathrm{mL}$ of Aloe vera extract (B), Apium graveolens (C), Sauropus androgynus (D), and combination of Aloe vera + Apium graveolens + Sauropus androgynus (E). JSM5000, SEM, 10,000×.

\section{DISCUSSION}

MRSA is one of the prominent pathogenic bacteria for human health. The MRSA causes severe infection with several clinical signs such as pneumonia and sepsis (Wanes, 2010); and purulent mass in the metatarsal joint (Babazadeh et al., 2015). Several studies described the treatment of this bacteria depends on the severity of the infection (Green et al., 2012). The drainage and incision on the skin abscess or cutaneous infection is the choice therapy to be done (Elston, 2007). It can be followed by daily cleansing and disinfectant to increase the chance of healing. The utilisation of antibiotics should follow the medical guideline (Ali et al., 2018), because failed therapy may cause multidrug resistant (Dissemond, 2009). Recently, one of the most popular treatments against bacterial infection is by using bioactive natural products.

A bioactive natural product can be synthesised from all part of plants body (Yang et al., 2016). In the tropical area including Indonesia, several herbs that are developed to produce bioactive natural product such as Aloe vera (AV), Apium graveolens (AG), and Sauropus androgynus (SA). Those three herbs are utilised both traditionally and in a modern way. The bioactive compound from those herbs can be collected by utilizing the extraction procedure such as ethanolic, alcoholic, and aqueous extraction (Sasidharan et al., 2011). The extraction is expected to isolate several bioactive compounds including alkaloid, flavonoid, saponin, tannin, phenolic, and its derivates (Kali, 2011). Furthermore, the extraction methods affect the biochemical constituent level (Zhang et al., 2018). For example, alcohol is used as the solvent to isolate the flavonoid, triterpenoid, sterol, tannin, polyphenol and alkaloid (Cai et al., 2014). AV, $\mathrm{AG}$, and SA have varied bioactive natural product both in qualitative and quantitative phytochemical screening. 
Based on quantitative phytochemical screening, AV contained the highest level of alkaloid, saponin, and tannin in a single extract compared to the others. However, AG has greater phytochemical compound regarding flavonoid and phenolic compared to AV and SA. Another finding showed that the combinations of those herbal extracts do not consistently increase the bioactive compound of the herb extracts. Surprisingly, the mixing of AV and AG decreases flavonoid, phenolic and saponin level. Several factors that are suspected impair the herbal extracts potency after combination are partial loss of the bioactive component because of the antagonist mechanism, and no typical pharmacological activity to one another. It is supported by the previous study that demonstrated the effects of piperine that decrease the bioavailability of all drugs, while some drugs effects were not consistent (Shaikh et al., 2009).

The antioxidant plays a significant role in controlling the oxidative stress of living things. The antioxidant activity of medicinal plant could be identified by determining its activity to break the chain of radicals. This study demonstrated that $\mathrm{AV}, \mathrm{AG}$, and $\mathrm{SA}$ are potential in scavenging DPPH in vitro. Although the mixing of herbs did not consistently increase the bioactive compound level, it still has high potency during DPPH scavenging. Those three herbal extracts support the potency of one another, it is proved by the increasing DPPH scavenging activity after the combination. The combination of herbal extracts could be used to protect the body from the destructive effects of free radicals (Meena et al., 2012). Furthermore, all three herbal extracts are tested regarding its antimicrobial activity using disc diffusion test and MIC. This study demonstrated that AV, AG, and SA have potential to inhibit the growth of MRSA in vitro. This potency is related to the bacteria's wall structure. The lipopolysaccharide in the membrane of MRSA is not as rigid as the lipopolysaccharide in the membrane of a Gram-negative bacteria, thus, the MRSA membrane can be destroyed by using hydrophilic solution such as AV, AG, and SA extracts (Seleshe et al., 2017). The extract combination triggers the synergic effects in inhibiting the MRSA colonisation in both solid and broth media. The destructive effects of antibiotic agents can be explored using SEM (Zajmi et al., 2015). This study revealed that MRSA cell walls can be destroy using the AV, AG and SA. Surprisingly, the dosage of $1 \mathrm{mg} / \mathrm{mL}$ of those extracts promote the damage of MRSA cell walls so that it can be utilised as the antimicrobial candidate for the MRSA infection based on the in vitro results. Those potential benefits of herbal extracts are witnessed due to the presence of a secondary metabolite of AV, AG, and SA. The plant's secondary metabolites such as tannin, saponin, flavonoid, alkaloid, and phenolic has a unique activity against pathogens, however, it depends on the solubility of the bioactive compounds (Al-Rifai et al., 2017).

\section{CONCLUSION}

In conclusion, Aloe vera, Apium graveolens, Sauropus androgynus have potential effects as antioxidant producer which also have potential as the chelating agent of 2, 2-diphenyl-1-picrylhydrazyl. Furthermore, these herbal extracts and its combination can be used as candidate for antibacterial agents, especially for methicillin resistant Staphylococcus aureus.

\section{DECLARATIONS}

\section{Authors' Contribution}

YAP and $\mathrm{K}$ designed the research. YAP, $\mathrm{K}$ and ADW performed the research. YAP, K, ADW, YPK wrote the manuscript. YAP and $\mathrm{K}$ edited the final form of the composed manuscript.

\section{Competing interests}

The authors have not declared any conflict of interests.

\section{Consent to publish} elsewhere.

All the authors were aware of the fact and agreed to be so named. The data of this study did not partially published

\section{Acknowledgements}

This research was funded by Final Assignment Recognition (RTA) of University of Gadjah Mada, Yogyakarta, Indonesia with grant number 47/RTA/UGM 2019. All the laboratory technicians from Dept. Microbiology, Faculty of Medicine, University of Airlangga and staffs from Integrated Laboratory, Faculty of Health, University of Muhammadiyah Sidoarjo were acknowledged for their assistant.

\section{REFERENCES}

Adhikari R, Pant ND, Neupane S, Neupane M, Bhattarai R, Bhatta S, Chaudhary R and Lekhak B (2017). Detection of methicillinresistant Staphylococcus aureus and determination of minimum inhibitory concentration of vancomycin for Staphylococcus aureus isolated from pus/wound swab samples of the patients attending a Tertiary Care Hospital in Kathmandu, Nepal. Canadian Journal of Infectious Diseases and Medical Microbiology, 2017: 2191532.2 DOI: https://doi.org/10.1155/2017/2191532.

Ajuru MG, Williams LF and Ajuru G (2017). Qualitative and quantitative phytochemical screening of some plants used in ethnomedicine in the Niger delta region of Nigeria. Journal of Food and Nutrition Science, 5(5): 198-205. DOI: https://doi.org/10.11648/j.jfns.20170505.16. 
Akar Z, Kucuk M and Dogan H (2017). A new colorimetric DPPH* scavenging activity method with no need spectrophotometer applied on synthetic and natural antioxidants and medicinal herbs. Journal of Enzyme Inhibition and Medical Chemistry, 32(1): 640-647. DOI: https://doi.org/10.1080/14756366.2017.1284068.

Ali MM, Helmy SM, El Desouky IE and Asfour HA (2018). Molecular characterization of Staphylococci isolated from cattle with mastitis. World's Veterinary Journal, 8(1): 9-18. PII: S232245681800002-8.

Al-Rifai A, Aqel A, Al-Warhi T, Wabaidur SM, Al-Othman ZA and Badjah-Hadj-Ahmed AY (2017). Antibacterial, antioxidant activity of ethanolic plant extracts of some Convolvulus species and their DART-ToF-MS profiling. Evidence-Based Complementary and Alternative Medicine, 2017; 2017: 5694305. DOI: https://doi.org/10.1155/2017/5694305.

Babazadeh D, Ghavami S, Nikpiran H and Dorestan N (2015). Acute Megabacteriosis and Staphylococcosis of canary in Iran. Journal of World's Poultry Research, 5(1): 19-20. PII: S2322455X1500003-5.

Bose R, Kumar MS, Manivel A and Mohan SC (2018). Chemical Constituents of Sauropus androgynus and Evaluation of its Antioxidant Activity. Research Journal of Phytochemistry, 12(1): 7-13. DOI: http://dx.doi.org/10.3923/rjphyto.2018.7.13.

Bussmann RW, Malca-Garcia G, Glenn A, Sharon D, Chait G, Diaz D, Pourmand K, Jonat B, Somogy S, Guardado G et al. (2010). Minimum inhibitory concentration of medicinal plants used Northern Peru as antibacterial remedies. Journal of Ethnophamacology, 132(1): 101-108. DOI: https://doi.org/10.1016\%2Fj.jep.2010.07.048.

Cai QY, Li WR, Wei JJ, Mi SQ and Wang NS (2014). Antinociceptive activity of aqueous and alcohol extract of Evodia rutaecarpa. Indian Journal of Pharmaceutical Sciences, 76(3): 235-239. DOI: https://www.ncbi.nlm.nih.gov/pmc/articles/PMC4090832/.

Carroll KC (2008). Rapid diagnostics for methicillin-resistant Staphylococcus aureus: current status. Molecular Diagnosis and Therapy, 12(1): 15-24. DOI: https://doi.org/10.1007/BF03256265.

Chabala LFG, Cuartas CEE and Lopez MEL (2017). Release behavior and antibacterial activity of chitosan/alginate blends with Aloe vera and silver nanoparticles. Marine Drugs, 15(10): 328. DOI: https://doi.org/10.3390/md15100328.

Danciu C, Zupko I, Bor A, Schwiebs A, Radeke H, Hancianu M, Cioanca O, Alexa E, Oprean C, Bojin F et al. (2018). Botanical therapeutics: phytochemical screening and biological assessment of chamomile, parsley, and celery extracts against A375 human melanoma and dendritic cells. International Journal of Molecular Sciences, 19(11): 3624. DOI: https://doi.org/10.3390/ijms19113624.

Dissemond J (2009). Methicillin resistant Staphylococcus aureus (MRSA): diagnostic, clinical relevance, and therapy. Journal of German Society of Dermatology, 7: 544-551. DOI: https://doi.org/10.1111/j.1610-0387.2009.07015.x.

Durai R, Ng PC and Hoque H (2010). Methicillin-resistant Staphylococcus aureus: an update. AORN Journal, 91(5): 599-606. DOI: https://doi.org/10.1016/j.aorn.2009.11.065.

Elston DM (2007). Community-acquired methicillin resistant Staphylococcus aureus. Journal of the America Academy of Dermatology, 56(1): 1-16. DOI: https://doi.org/10.1016/j.jaad.2006.04.018.

Fadeev SB and Nemtseva NV (2009) Formation of biofilms by agents of surgical soft tissue infections. Zhurnal Mikrobiologii Epidemiologii, I immunobiologii, 4: 114-117. DOI: https://www.ncbi.nlm.nih.gov/pubmed/19715215.

Green BN, Johnson CD, Egan JT, Rosenthal M, Griffith EA and Evans MW (2012). Methicillin-resistant Staphylococcus aureus: an overview for manual therapists. Journal of Chiropractic Medicine, 11(1): 64-76. DOI: https://doi.org/10.1016/j.jcm.2011.12.001.

Haasbroek A, Willers C, Glyn M, Du Plessis L and Hamman J (2019). Intestinal drug absorption enhancement by Aloe vera gel and whole leaf extract: in vitro investigations into the mechanisms of action. Pharmaceutics, 11(1): 36. DOI: https://doi.org/10.3390/pharmaceutics11010036.

Hamman JH (2008). Composition and applications of Aloe vera leaf gel. Molecules, 13(8): 1599-1616. DOI: https://doi.org/10.3390/molecules13081599.

Himratul-Aznita WH, Mohd Al Faisal N and Fathilah AR (2011). Determination of the percentage inhibition of diameter growth (PIDG) of Piper betle crude aqueous extract against oral Candida species. Journal of Medicinal Plants Research, 5(6): 878884. DOI: http://eprints.um.edu.my/id/eprint/3396.

Kali A (2011). Antibiotics and bioactive natural products in treatment of methicillin-resistant Staphylococcus aureus: a brief review. Pharmacognosy Review, 9(17): 29-34. DOI: https://dx.doi.org/10.4103\%2F0973-7847.156329.

Kooti W and Daraei N (2017). A review of the antioxidant activity of celery (Apium graveolens L). Journal of Evidence-Based Complementary Medicine \& Alternative Medicine, 22: 1029-1034. DOI: https://dx.doi.org/10.1177\%2F2156587217717415.

Kumar S, Mishra M, Wahab N and Warikoo R (2014). Larvacidal, repellent, and irritant potential of the seed-derived essential oil of Apium graveolens against Dengue vector, Aedes aegypti (Diptera: Culicidae). Frontiers Public Health, 2: 147. DOI: https://doi.org/10.3389/fpubh.2014.00147.

Meena H, Pandey HK, Pandey P, Arya MC and Ahmed Z (2012) Evaluation of antioxidant activity of two important memory enhancing medicinal plants Bacoppa monnieri and Centella asiatica. Indian Journal of Pharmacology, 44: 114-117. DOI: https://doi.org/10.4103/0253-7613.91880.

Missiakas DM and Scheneewind O (2013). Growth and laboratory maintenance of Staphylococcus aureus. Current Protocols in Microbiology, 9: 9C.1. DOI: https://doi.org/10.1002/9780471729259.mc09c01s28.

Otto M (2010). Basis of virulence in community-associated methicillin-resistant Staphylococcus aureus. Annual Review of Microbiology, 64: 143-162. DOI: https://doi.org/10.1146/annurev.micro.112408.134309.

Powanda MC, Whitehouse MW and Rainsford KD (2015). Celery seed and related extracts with antiarthritic, antiulcer, and antibacterial activities. Progress in Drug Research, 70: 133-153. DOI: https://www.ncbi.nlm.nih.gov/pubmed/26462366.

Prabhu A, Madhushree M and Devasya RP (2015). Phytochemical constituents and antioxidants activities of some plants commonly used in India traditional diet. Journal of Applied Pharmaceutical Science, 5(11): 108-112. DOI: https://dx.doi.org/10.7324/JAPS.2015.501118. 
Prakoso YA and Kurniasih (2018). The effects of Aloe vera cream on the expression of CD4+ and CD8+ lymphocytes in skin wound healing. Journal of Tropical Medicine, 2018: 6218303. DOI: https://doi.org/10.1155/2018/6218303.

Prakoso YA, Puspitasari, Rini CS, Aliviameita A, Salasia SIO, Kurniasih, Ikram AFD, Walalangi B, Utama KP, Al-Huda MF and Su'udiyah NA (2018). The role of Sauropus androgynus (L.) Merr leaf powder in the broiler chickens fed a diet naturally contaminated with aflatoxin. Journal of Toxicology, 2018: 2069073. DOI: https://dx.doi.org/10.1155\%2F2018\%2F2069073.

Sasidharan S, Chen Y, Saravanan D, Sundram KM and Latha LY (2011). Extraction, isolation, and characterization of bioactive compounds from plant's extracts. African Journal of Traditional, Complementary and Alternative Medicines, 8(1): 1-10. DOI: https://www.ncbi.nlm.nih.gov/pubmed/22238476.

Seleshe S, Lee JS, Lee S, Lee HJ, Kim GR, Yeo J, Kim JY and Kang SN (2017). Evaluation of antioxidant and antimicrobial activities of ethanol extracts of three kinds of strawberries. Preventive Nutrition and Food Science, 22(3): 203-210. DOI: https://doi.org/10.3746/pnf.2017.22.3.203.

Shaikh J, Ankola DD, Beniwal V, Singh D and Kumar MN (2009). Nanoparticle encapsulation improves oral bioavailability of curcumin by at least 9 -fold when compared to curcumin administered with piperine as absorption enhancer. European Journal of Pharmaceutical Sciences, 37(3-4): 223-230. DOI: https://doi.org/10.1016/j.ejps.2009.02.019.

Talmadge J, Chavez J, Jacobs L, Munger C, Chinnah T, Chow JT, Williomson D and Yates K (2004). Fractination of Aloe vera L. inner gel, purification, and molecular profiling of activity. International Immunopharmacology, 4: 1757-1773. DOI: https://doi.org/10.1016/j.intimp.2004.07.013.

Waness A (2010). Revisiting methicillin-resistant Staphylococcus aureus infections. Journal of Global Infectious Diseases, 2: 49-56. DOI: https://doi.org/10.4103/0974-777X.59251.

Yang L, Yang C, Li C, Zhao Q, Liu L, Fang X and Chen XY (2016). Recent advances in biosynthesis of bioactive compounds in traditional Chinese medicinal plants. Science Bulletin Beijing, 61: 3-17. DOI: https://doi.org/10.1007/s11434-015-0929-2.

Zajmi A, Hashim NM, Noordin MI, Khalifa SAM, Ramli F, Ali HM and El-Seedi HR (2015). Ultrastructural study of antibacterial activity of artonin E versus streptomycin against Staphylococcus aureus strains. PLoS ONE, 10: e0128157. DOI: https://doi.org/10.1371/journal.pone.0128157.

Zhang QW, Lin LG and Ye WC (2018). Techniques for extraction and isolation of natural products: a comprehensive review. Chinese Medicine, 13: 20. DOI: https://doi.org/10.1186/s13020-018-0177-x. 